\title{
Prototecosis canina: primer reporte en Argentina
}

\author{
Spampinato, M.F.'; Kujman, S. ${ }^{2}$; Cantón, J. ${ }^{3}$; Daglio, C. ${ }^{3}$; Catena, M. ${ }^{3}$ \\ ${ }^{1}$ Centro Endoscopia y Gastroenterología Veterinaria (CEGAVE), French 4718, Mar del Plata (7600), Argentina. \\ ${ }^{2}$ Servicio Anatomía Patológica Veterinaria, Mar del Plata. ${ }^{3}$ Área de Enfermedades Infecciosas, Fac.Cs.Vet. \\ (Univ.Centro Prov.Bs.As.), Tandil. E-mail: spampinato@cegave.com
}

\begin{abstract}
Resumen
Spampinato, M.F.; Kujman, S.; Cantón, J.; Daglio, C.; Catena, M.: Prototecosis canina: primer reporte en Argentina. Rev. vet. 28: 2, 168-171, 2017. La prototecosis es una enfermedad infecciosa causada por algas del género Prototheca, que afecta a animales y seres humanos. El objetivo del presente trabajo fue reportar un caso de prototecosis en una perra bulldog francés de 3 años oriunda de la ciudad de Mar del Plata, Argentina, con antecedentes de diarrea hemorrágica crónica sin respuesta al tratamiento convencional. La citología de mucosa rectal y las biopsias endoscópicas mostraron abundantes organismos levaduriformes compatibles con Prototheca zopfii. Se detallan los hallazgos clínicos, endoscópicos, citológicos e histopatológicos. De acuerdo a la investigación efectuada por los autores, este es el primer caso de prototecosis canina reportado en la Argentina.
\end{abstract}

Palabras clave: perro, Prototheca, diarrea hemorrágica, citología, histopatología.

\begin{abstract}
Spampinato, M.F.; Kujman, S.; Cantón, J.; Daglio, C.; Catena, M.: Canine protothecosis: first report in Argentina. Rev. vet. 28: 2, 168-171, 2017. Protothecosis is an infectious disease caused by algae of the genus Prototheca, which affects animals and human beings. The aim of the present article was to report a case of protothecosis in a 3 year old, female, French bulldog from the city of Mar del Plata, Argentina, with a history of chronic hemorrhagic diarrhea without response to conventional treatment. Rectal cytology and endoscopic biopsies showed abundant levaduriform organisms compatible with Prototheca zopfii. Clinical, endoscopic, cytological and histopathological findings are detailed. To the authors knowledge, this is the first case of canine protothecosis reported in Argentina.
\end{abstract}

Key words: dog, Prototheca, hemorrhagic diarrhea, cytology, histopathology.

\section{INTRODUCCIÓN}

La prototecosis es una enfermedad infecciosa rara que afecta a animales y seres humanos, causada por algas aclorofílicas del género Prototheca, las cuales se encuentran distribuidas en todo el mundo, pudiendo hallarse en cuerpos de agua corriente o estancada, suelo, árboles, alimentos, leche de vaca y en las heces fecales de seres humanos y animales ${ }^{2,4}$.

Las especies de Prototheca reconocidas actualmente incluyen $P$. stagnora, $P$. ulmea, P. blaschkeae, $P$. zopfii y $P$. wickerhamii ${ }^{4}$, siendo las dos últimas las patógenas para el hombre y los animales ${ }^{2,4,7}$. Estos microorganismos saprófitos poseen bajo potencial patógeno en los mamíferos y se sugiere que los individuos inmunosuprimidos presentan mayor riesgo de infección $^{4,7}$.

Recibido: 7 marzo 2017 / Aceptado: 18 julio 2017

Trabajo presentado en el II Congreso Internacional de Medicina

Animal, Tandil, Argentina, 2016.
La mayoría de los perros infectados son adultos jóvenes, con edades medias de 4 a 6,8 años ${ }^{5,7}$ y se ha mencionado una probable predisposición en las razas Collie y Boxer ${ }^{7}$. El contagio se produce por ingestión y también por contacto a través de la piel o mucosas dañadas ${ }^{2}$, siendo la primera vía la más probable en los perros ${ }^{7}$.

A diferencia de los felinos y bovinos, en donde la presentación cutánea es la más habitual ${ }^{1,7}$, la mayoría de los caninos sufre una infección sistémica de curso progresivo y fatal, con diarrea hemorrágica subaguda a crónica y signos neurológicos, incluyendo ceguera. Las lesiones oculares se reportan hasta en los dos tercios de los casos, mientras que la enfermedad ocular primaria sin compromiso sistémico es rara. Las lesiones cutáneas no asociadas a enfermedad sistémica también son infrecuentes en perros ${ }^{5}$.

Además, una gran variedad de signos clínicos han sido reportados en caninos; algunos de ellos abarcan fiebre, polidipsia-poliuria, incontinencia urinaria, depresión, cambios de conducta, dolor cervical, signos vestibulares, ataxia, paresia, convulsiones y claudica- 
ción debida a osteomielitis ${ }^{7}$. Los signos oculares son dolor, blefarospasmo, edema corneal, uveítis anterior, turbidez del humor acuoso e inyección de vasos epiesclerales, en tanto que la ceguera es generalmente secundaria a desprendimiento de retina por una coriorretinitis exudativa ${ }^{5}$.

Las lesiones macroscópicas consisten en nódulos blancos a grises de 1 a $3 \mathrm{~mm}$, $\mathrm{u}$ ocasionales estriaciones distribuidas en múltiples tejidos como intestino grueso, ojos, cerebro, riñón, hígado, músculo esquelético, miocardio, linfonódulos, glándula tiroides, páncreas, peritoneo y diafragma ${ }^{6-8}$.

La colonoscopía revela usualmente un colon con pliegues engrosados, con mucosa friable, ulcerada y con zonas desprendidas y necrosadas ${ }^{3}$. La enfermedad puede ser diagnosticada por citología, histopatología y/o cultivo en la mayoría de los casos ${ }^{2,4-8}$, aunque también por inmunofluorescencia indirecta y $\mathrm{PCR}^{6}$. El cultivo del microorganismo puede efectuarse a partir de humor vítreo, sangre, líquido cefalorraquídeo, lesiones cutáneas, orina, materia fecal, raspados o biopsias de mucosa rectal o colónica, como así también desde otros tejidos que se encuentren afectados ${ }^{7}$.

Las especies de Prototheca se desarrollan en agar sangre y en medios de cultivo comunes para hongos, creciendo rápidamente en agar dextrosa Sabouraud (sin cicloheximida) a $25-37^{\circ} \mathrm{C}$, formando colonias blancas o cremosas de 1-3 mm de diámetro, generalmente dentro de las $48 \mathrm{~h}^{5,7}$.

\section{MATERIAL Y MÉTODOS}

Un canino bulldog francés, hembra, de 3 años, fue derivado a CEGAVE por un cuadro de diarrea hemorrágica profusa de al menos 7 meses de evolución, indiferente a los tratamientos sintomáticos convencionales. La paciente era mascota única, habitaba en un departamento y en ocasiones nadaba en el mar y en una laguna cercana a la ciudad. En el examen clínico presentaba un score corporal de 3/5 y durante la consulta defecaba constantemente materia fecal mucosa roja oscura. $\mathrm{La}$ temperatura rectal era $38,5^{\circ} \mathrm{C}$.

En la semiología ocular se evidenciaba falta de respuesta de amenaza y a simple vista desprendimiento de retina en ojo izquierdo; en ojo derecho presentaba prueba de amenaza positiva y vitritis. Además se observaba una foliculitis superficial en abdomen, ingle y base de la cola. Los estudios coproparasitológicos, hematológicos y de orina realizados previamente no presentaban alteraciones.

Se decidió realizar estudio endoscópico de colon, en el cual se observó la mucosa rectal con aspecto inflamatorio y con pliegues engrosados, y la mucosa colónica con aspecto granular, coloración disminuida, desprendimiento de la mucosa y úlceras. A $20 \mathrm{~cm}$ del esfínter anal se encontró además una estenosis previa a la curvatura derecha o esplénica.

Se efectuaron biopsias bajo guía endoscópica de mucosa rectal y colónica. Se instauró un tratamiento paliativo con metronidazol $15 \mathrm{mg} / \mathrm{kg}$ cada $12 \mathrm{~h}$, enrofloxacina $5 \mathrm{mg} / \mathrm{kg}$ cada $24 \mathrm{~h}$ y dieta casera a base de arroz, pollo y tofú, con la adición de fibra soluble (Psyllium). Siete días después la paciente no presentó cambios positivos y los nuevos resultados de hemograma, bioquímica y análisis de orina fueron normales.

Se tomó una muestra de materia fecal y se realizó hisopado rectal para citología y cultivo. La materia fecal y el hisopo para cultivo se enviaron para su análisis al área de Enfermedades Infecciosas de la Facultad de Ciencias Veterinarias de Tandil.

\section{RESULTADOS}

En los frotis teñidos con Tinción 15 se visualizaron abundantes bacterias de forma bacilar y neutrófilos, así como moderada cantidad de microorganismos levaduriformes unicelulares, de 10 a $20 \mu \mathrm{m}$, ovoides y levemente curvados, intensamente basófilos, con una cápsula blanca y refringente (Foto 1). Algunas estructuras eran más grandes y estaban esporuladas, conteniendo 2 a 8 endosporas dispuestas radialmente.

En la histopatología se observaron múltiples estructuras similares a las descriptas en la citología, PASpositivas, que se disponían libres sobre la superficie de la mucosa y también extracelularmente en la lámina propia superficial (Foto 2). Además, la mucosa estaba erosionada multifocalmente y en lámina propia se visualizaba un infiltrado inflamatorio linfoplasmocítico moderado, con presencia de fibrosis leve.

El diagnóstico cito-histopatológico emitido por el Servicio de Anatomía Patológica Veterinaria fue colitis erosiva, linfoplasmocítica, moderada, crónica, con organismos compatibles con Prototheca zopfii, en base a la morfología descripta por Stenner y col ${ }^{7}$.

A los 7 días de incubación en agar Sabouraud a $37^{\circ} \mathrm{C}$ se observó el desarrollo de colonias blanquecinas redondas de bordes irregulares. Con la coloración de

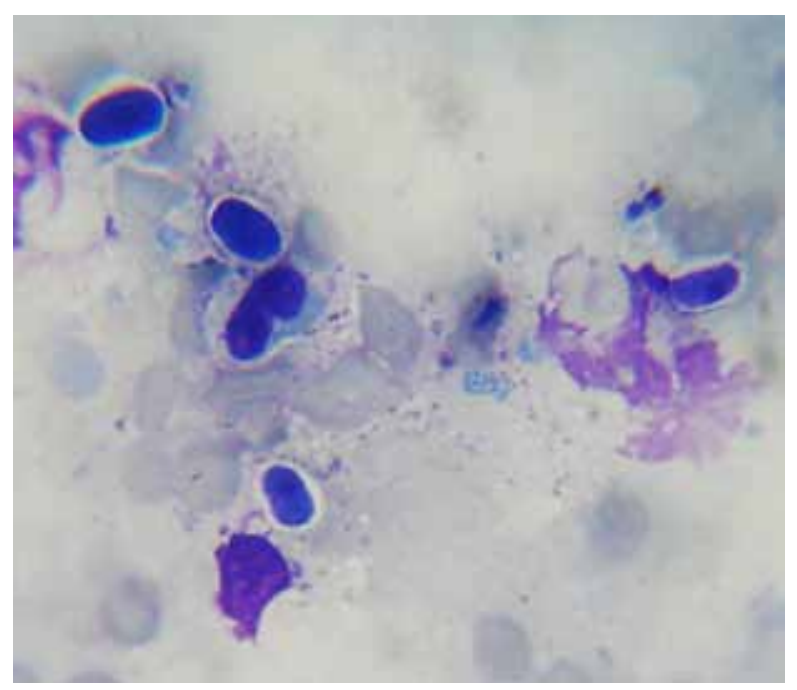

Foto 1. Citología de hisopado rectal. Se aprecia un leucocito y cuatro formas levaduriformes ovoides con una cápsula blanca refringente. Esta morfología es consistente con P. zopfii. (Tinción 15, 100x). 


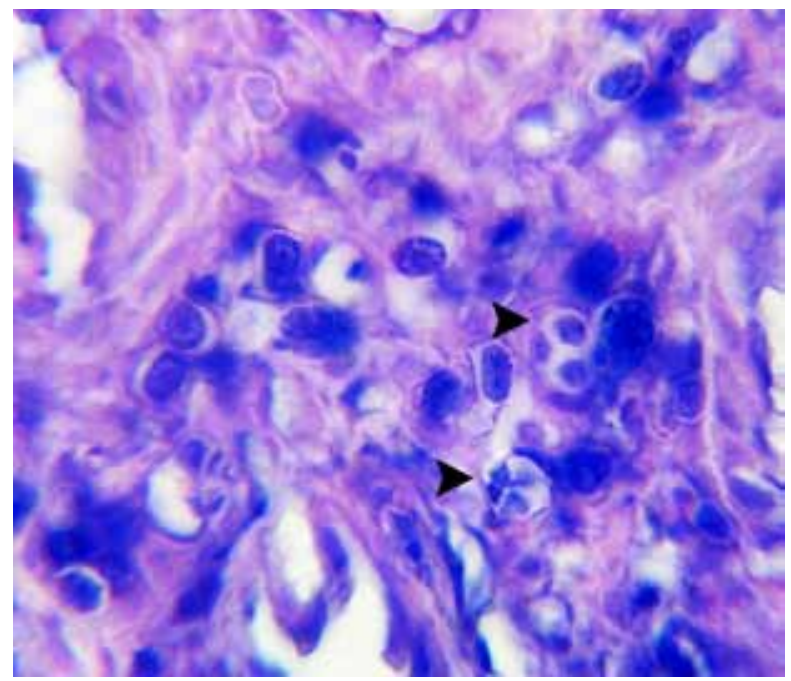

Foto 2. Histopatología de mucosa colónica. Múltiples estructuras levaduriformes en lámina propia, basófilas y rodeadas por una cápsula blanca. Se observan dos formas esporuladas (flechas) (HE, 100x).

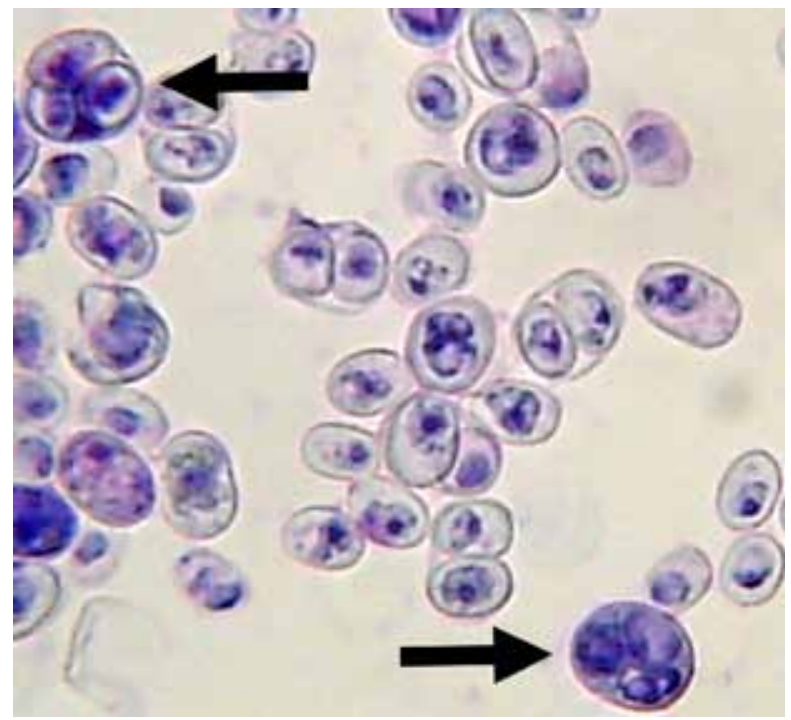

Foto 3. Citología realizada a partir del cultivo. Nótese la correlación morfológica de las estructuras esporuladas (flechas) con las del corte histológico de la Figura 2.

Gram y con Tinción 15 se observaron estructuras redondeadas compatibles con Prototheca spp (Foto 3).

Se comenzó el tratamiento específico con itraconazol $5 \mathrm{mg} / \mathrm{kg}$ cada $12 \mathrm{~h}$ durante una semana, luego 5 $\mathrm{mg} / \mathrm{kg}$ cada $24 \mathrm{~h}$ y dosis crecientes $(0,25 \mathrm{mg} / \mathrm{kg}$ hasta 1 $\mathrm{mg} / \mathrm{kg}$ ) de anfotericina $\mathrm{B}$ en complejo lipídico vía endovenosa lenta en dextrosa al 5\%, 3 veces por semana. Además se agregó mesalacina $10 \mathrm{mg} / \mathrm{kg}$ cada $12 \mathrm{~h}$.

A los 10 días post tratamiento el examen ocular reveló midriasis, vasos epiesclerales inyectados y vitritis, con desprendimiento total de retina y placas blanquecinas en ambos ojos (Foto 4). A los 60 días la paciente comenzó a defecar normalmente y recuperó peso. Cuatro meses post tratamiento los dueños decidieron suspender la administración de anfotericina $\mathrm{B}$ y la perra tuvo una recaída, falleciendo a las dos semanas.

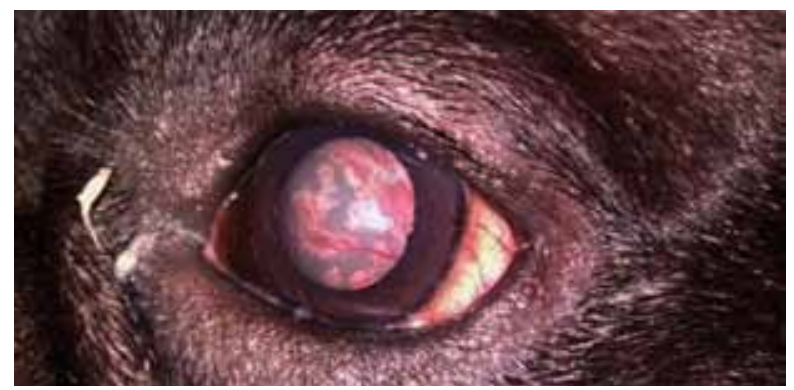

Foto 4. Ojo izquierdo con placas blanquecinas irregulares.

\section{DISCUSIÓN}

Lamentablemente, los propietarios del animal no accedieron a realizar análisis clínicos adicionales, y tampoco aceptaron efectuar la necropsia, lo cual hubiera aportado mayor información acerca de los órganos afectados. En base a la anamnesis, se sospecha que esta perra pudo haberse contagiado de prototecosis al beber agua estancada de la laguna que frecuentaba, tal como sugieren investigadores australianos ${ }^{7}$.

El primer reporte mundial de prototecosis canina ocurrió en Estados Unidos, en 1969. Desde entonces la enfermedad se ha diagnosticado en perros de varias regiones del mundo incluyendo Inglaterra, España, Grecia, Sudáfrica, Australia, Japón y Brasil ${ }^{6,7}$. En 2002 se detectó $P$. zopfii en aguas contaminadas de Argentina ${ }^{9}$, y se sabe que provoca mastitis en vacas de este país desde $1996^{1}$. Según la revisión bibliográfica realizada por los autores, éste es el primer caso de prototecosis canina reportado en la Argentina.

En conclusión, se debe tener en cuenta a esta enfermedad en perros con diarrea hemorrágica crónica que no responde a tratamientos convencionales, e informar a la población para evitar que sus mascotas beban agua estancada de lagunas u otros cuerpos de agua. Además, dada su relevancia en salud pública, se resalta la importancia de arribar a un diagnóstico temprano a fin de prevenir adecuadamente a los propietarios del animal.

Agradecimientos. Por su colaboración y aporte de datos sobre la enfermedad en bovinos, a la Dra. Adriana Schettino (FCV-Tandil). Al Dr. Andrés Sigismondi por su Servicio de Anestesia y a la Dra. Silvia Contreras del Servicio de Oftalmología de la ciudad.

\section{REFERENCIAS}

1. Calvinho LF, Ganre V, Neder V. 2012. Mastitis por Prototheca zopfi: características principales, diagnóstico y control. Diario del veterinario, INTA Centro Regional Santa Fé. Proyecto Lechero $\mathrm{N}^{\circ} 4$.

2. Greene CE. 2012. Infectious diseases of the dog and cat, $4^{\text {th }}$ ed., Elsevier Saunders, St. Louis, USA, $1376 \mathrm{p}$.

3. Hall E, Simpson JW. 2012. Manual de gastroenterología en pequeños animales, $2^{\text {nd }}$ ed., Lexus, Barcelona, $492 \mathrm{p}$.

4. Lass-Flörl C, Mayr A. 2007. Human Protothecosis. Clin Microbiol Rev 20: 230-242. 
5. Shank AM, Dubielzig RD, Teixeira LB. 2015. Canine ocular protothecosis: A review of 14 cases. Vet Ophthalmol 18: 437-442.

6. Souza LN, Estrela A, Moreira EL, Ribeiro LG, Xavier MN, Silva TM, Costa EA, Santos RL. 2009. Systemic canine protothecosis. Braz J Vet Pathol 2: 102-106.

7. Stenner VJ, Mackay B, King T, Barrs VR, Irwin P, Abraham L, Swift N, Langer N, Bernays M, Hampson E, Martin P, Krockenberger MB, Bosward K, Latter M, Malik R. 2007. Protothecosis in 17 Australian dogs and a review of the canine literature. Med Mycol 45: 249266.
8. Van Kruiningen HJ, Garner FM, Schiefer B. 1969. Protothecosis in a dog. Pathologica Vet 6: 348-354.

9. Vigna MS, Galvagno MA, Alberghina J, Del Mónaco SM. 2002. Prototheca zopfii (Chlorophyta) capaz de utilizar "gas oil", registrada por primera vez en aguas contaminadas de Argentina. Darwiniana 40: 45-50. 